\title{
Research Trend on Water Tank Automation
}

\author{
Peng Cheng1), Garima Nautiyal2)
}

\begin{abstract}
This paper aims to present a new concept of automatic tank filling system. A typical household water tank uses a ball mechanism to control the filling of water in the tank. The process is not automatic as the motor used has to be operated manually. The automatic systems uses costly electronic sensors. The new concept which is being presented is without the use of any electronic component. The idea behind the water tank automation is that as soon the water level goes down at $10 \%$, the motor automatically switches on and as soon the water level reaches to $90 \%$ of the total height, the motor automatically switches off. This process is controlled and automated using a programmable logic controller (PLC) through a ladder logic. Water tank automation will aid in an increased energy saving.
\end{abstract}

Keywords: Automation, Water automation, PLC, Water Level, Water level

\section{Introduction}

Building automation for the home is called home automation. It involves control and automation of heating, lighting, air conditioning, utilization, as well as the appliances used at home like washing machines, refrigerators, dishwasher, etc.

Water tank automation is also an important part of home automation. The word automation refers to the programming and scheduling of events for the devices connected through programming which can include time related command or position related commands [1-4].

The new idea of water tank automation being presented here is with the use of programmable logic control. The overhead water tank is fitted at the terrace of nearly every household. It supplies water for domestic purposes with a dc motor wherein the switching has been a manual process until recently where the process was automated using sensors. The idea presented in this paper is to remove the need of costly sensors replacing them with simple electrical wires and tank water itself is used in a completing the electric circuit. The supply is given by the PLC and is programmed (i.e., using ladder logic) such that the motor is turned on as soon as the water level goes below $10 \%$ of the total capacity and switches off the motor as soon as water level crosses $90 \%$.

Received(August 10, 2017), Review Result(1st: August 31, 2017, 2nd: October 17, 2017), Accepted(December 10, 2017)

${ }^{1}$ Department of Electrical Engineering, Hunan University of Technology, China

email: PengCheng_wlwl@126.com

${ }^{2}$ (Corresponding Author) Department of Electrical Engineering, THDC Institute of Hydropower Engineering and Technology email: nautiyalgarima990@gmail.com 


\section{Design of the Tank}

The tank is designed in a different way where 3 points are designated on the 3 parts of the tank that is used for sensing the water level using electric based wire sensors and each senses for low, middle and full levels of the water.

Each input can be connected to the PLC and the output is connected to the motor. There will be another wire sensor that will always be connected to the supply to the PLC so that the wire will act as a push button to the water that is already converted to the electrolyte solution [5-8].

Thus, there will be 4 wire sensors in the tank which are identified as

- Common Sensor

- Low Sensor

- Middle Sensor

- Full Sensor

The Common sensor will always be common, i.e., the supply will be always available.

Low sensor with $10 \%$ level of water.

Middle sensor with $50 \%$ level of water.

Full sensor with $90 \%$ level of water.

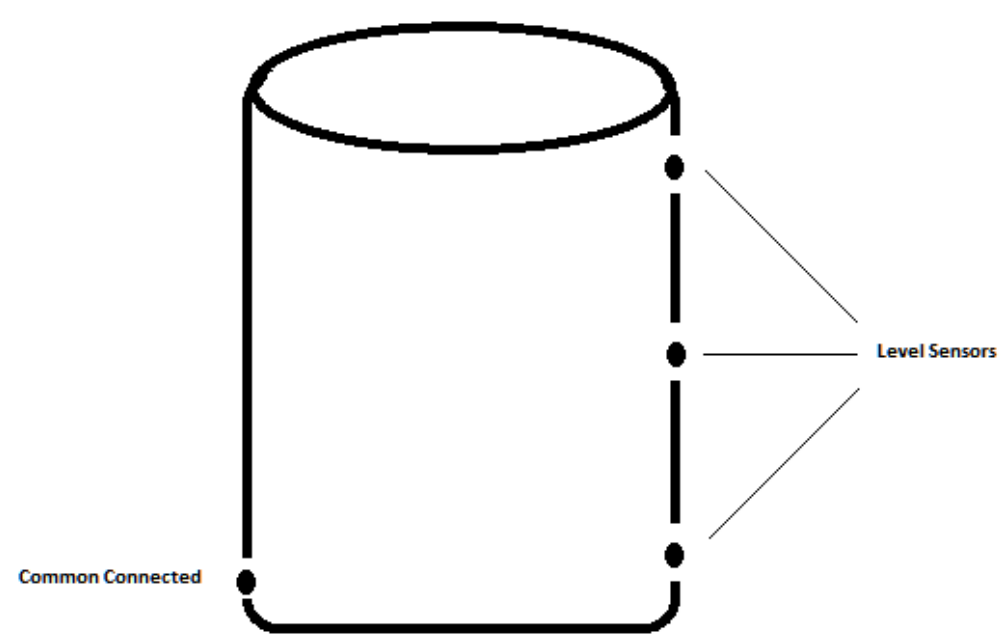

[Fig. 1] Design of the tank

3. Methodology Involved 
The methodology demonstrates the implementation of the idea being presented in this paper.

The hardware involves a small container of about half liter capacity symbolizing the water tank. The motor used is DC which is also called tullu motor having a voltage rating of $12 \mathrm{v}$ and three wires have been fitted to the tank at different levels, such that, a wire is fitted to $10 \%$ level of the total capacity, where second is fitted to $50 \%$ level, and the third wire is fitted to $90 \%$ level and these three wires are connected to the input part of the PLC. Another wire is fitted at the bottom position of the tank which is used for completing the circuit. The tank is initially filled at $10 \%$ level of tap water which conducts electricity as it has dissolved salts that dissociate into ions when electricity is passed through. These ions are responsible for the electrical conductivity of tap water. These salts are present in a very small quantity in tap water so its conductivity is low. Due to its low conductivity, it is not able to give input signal to PLC. In order to increase its conductivity, a small amount of sodium chloride is added to the water so that a DC current is passed using two aluminum electrodes which causes electrolysis of salts. As a result of electrolysis, the conductivity of water increases and it becomes capable to conduct enough current in giving signals to the PLC. As the water is at $10 \%$ level, the wire-1 provides input signal to the PLC. Since the PLC output part is connected to the DC pump, the PLC gives signal to the DC pump to start pumping water to the tank. As soon as the water reaches $90 \%$ level of total tank capacity, wire-3 start conducting electricity and send input signal to the PLC. Then, as the PLC senses the input, it sends an output signal to the DC pump to stop pumping water into the tank. Whenever the tank is emptied and the water level again reaches at $10 \%$, the PLC sends the output signal to the DC pump and start pumping water again. The electrolysis will be done through the 24 volt and ground terminal of the PLC for a limited seconds and it is done if a voltage drop will be sensed by AVR controller.

The PLC is programmed through ladder logic as shown in Figure 2. 


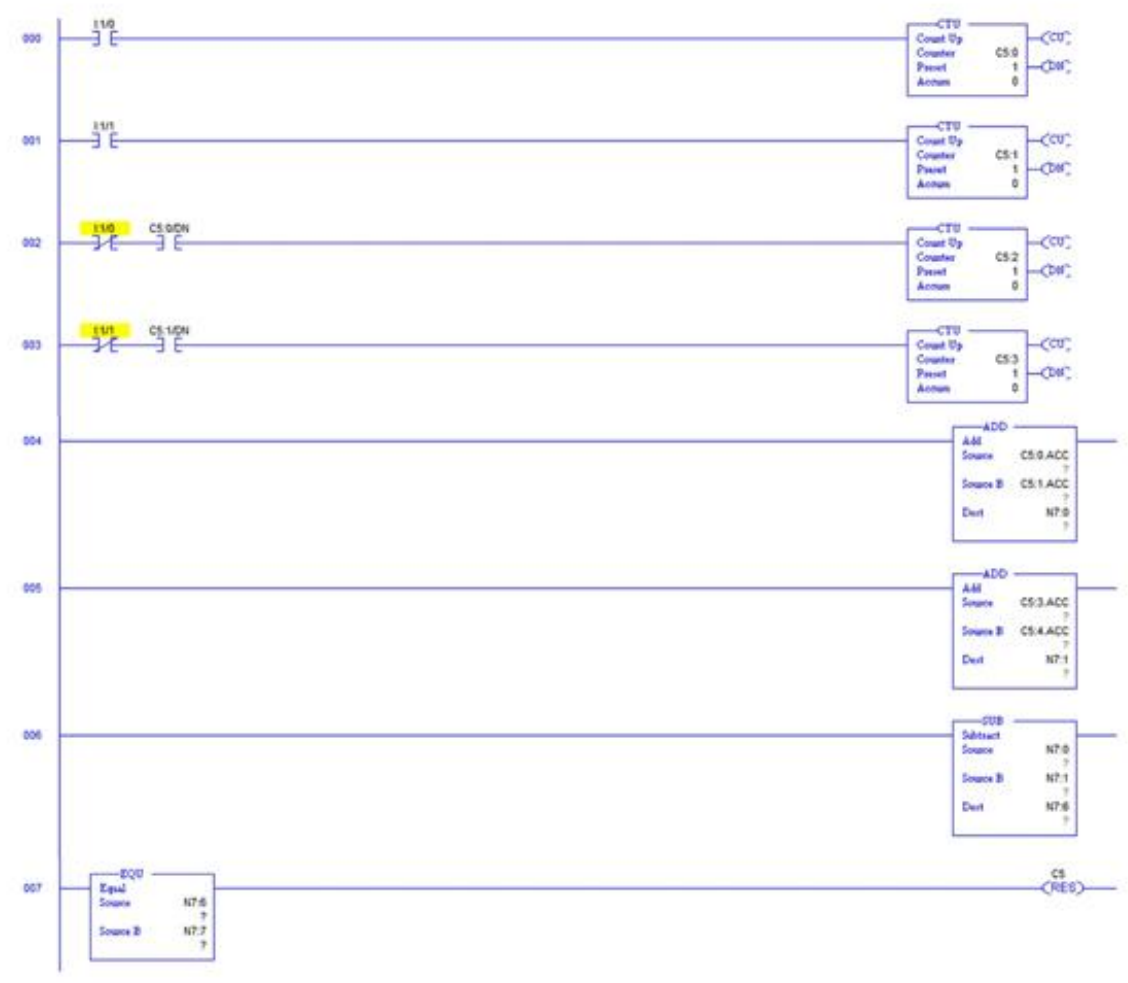

[Fig. 2] Ladder Logic of system

\section{Future Scope and Conclusion}

"Prediction is very difficult, especially if it's about the future" said Neil Bohr, a Danish Physicist and Nobel prize winner. With today's potential for quantum loops in technology seismic shifts in economics and rapid change in political pressure, this statement is never and has never been perhaps, so true.

So, when it comes to water tank automation it has been tried to extrapolate from trends inside and outside the utility space including the current challenges, technology advances and consumer behavior.

The concept presented in this paper is very simple, yet effective.

This whole idea can be extended to overhead household water tank, to water Tankers and also has a wide range of industrial application. It will help in reducing the wastage of water and electricity and into a lower cost.

For large localities, a single central system can be established for doing the same work for cost effectiveness and also for better results. 


\section{References}

[1] Zittel Werner, Wurster Reinhold, "Chapter 3: Production of Hydrogen. Part 4: Production from electricity by means of electrolysis", HyWeb: Knowledge - Hydrogen in the Energy Sector, Ludwig-Bölkow-Systemtechnik $\mathrm{GmbH},(1996)$

[2] Technology.org, "Scientists develop a water splitter that runs on an ordinary AAA battery". August (2014)

[3] Badwal SPS., Giddey S., Munnings C., "Hydrogen production via solid electrolytic routes". WIRES Energy and Environment, Vol.2, No.5, pp.473 - 487, DOI: 10.1002/wene.50, (2012)

[4] Tilley, R. J. D., Understanding solids: the science of materials. John Wiley and Sons, pp.281, ISBN978-0-470-85276-7, (2004)

[5] Machunda Revocatus L., Hyungkuk Ju, Jaeyoung Lee, "Electrocatalytic reduction of CO2gas at Sn based gas diffusion electrode", Current Applied Physics, Vol.11, No.4, DOI: 10.1016/j.cap.2011.01.003, (2011)

[6] Edward W. Kamen, Industrial Controls and Manufacturing, Chapter 8 Ladder Logic Diagrams and PLC Implementations, AcademicPress, (1999) ISBN 0123948509

[7] R. Fehr, The Basics of Ladder Logic, Dec 1, http://ecmweb.com/archive/basics-ladder-logic, (2003)

[8] Ryan G. Rosandich, What to know about PLC ladder diagram programming, Jun 1, http://ecmweb.com/archive/basics-ladder-logic, (2002) 